\title{
Factors Influencing Students' Perceived Difficulties in Studying Geometry: A Case of Konogo-Odumasi, Ghana
}

\author{
Kennedy Oduro Aboagye1, Yan Denk Ke², David Anim Mante1 \\ ${ }^{1}$ School of Teacher Education, Huzhou University, Huzhou, China \\ ${ }^{2}$ Huzhou University, Huzhou, China \\ Email: kennedabs360@gmail.com, zsydk@163.com, jasonmante2018@yahoo.com
}

How to cite this paper: Aboagye, K. O., Ke, Y. D., \& Mante, D. A. (2021). Factors Influencing Students' Perceived Difficulties in Studying Geometry: A Case of KonogoOdumasi, Ghana. Open Journal of Social Sciences, 9, 526-540.

https://doi.org/10.4236/jss.2021.99038

Received: August 25, 2021

Accepted: September 23, 2021

Published: September 26, 2021

Copyright (อ 2021 by author(s) and Scientific Research Publishing Inc. This work is licensed under the Creative Commons Attribution International License (CC BY 4.0).

http://creativecommons.org/licenses/by/4.0/

(c) (i) Open Access

\begin{abstract}
The study of geometry is so important because it is associated with more academic and career opportunities and, at the same time, acts as one of the critical filters for entry into higher education programs and even in the world of work. The purpose of the study was to investigate the factors influencing the perceived difficulties of studying geometry in Konongo Odumasi Municipal area in the Asante Akim Central Municipal. The study adopted a descriptive survey design and also collected data through the use of a questionnaire. The study used the stratified sampling technique to select a sample of $150 \mathrm{stu}-$ dents. The study found that parents' education level and environmental factors around the classroom were significant factors influencing perceived difficulties of geometry. The study concluded that parents' educational level and environmental factors are good predictors of perceived difficulties in geometry, and also gender is a good factor in predicting the level of perceived difficulties of geometry among students in the classroom. It is recommended that teachers and education institutions ensure a sound environment that promotes geometry with ease without any difficulty. Parental guidance should also be encouraged to create an atmosphere where wards would not have to look down upon parental educational level and be discouraged from asking for help in geometry.
\end{abstract}

\section{Keywords}

Mathematics, Geometry, High School, Student

\section{Introduction}

\subsection{Background of Study}

Mathematics has been the knowledge that people use in their daily life. Other 
sciences, such as natural science, economics, and others, have also used mathematics. Maths has been studied formally from elementary school. On the other hand, mathematics has been studied informally since a child's early years. Mathematics has been a way of thinking, arranging logical evidence, and communicating through a teaching-learning process, according to Ganal and Guiab (2014). According to the assertion, mathematics has been a lesson in paradigm, pattern, relationship, organization, and worldview, according to Satriawan and Wutsqa (2013). The subject of mathematics received a lot of attention. As a result, there are various branches of mathematics that can be studied. Geometry is a field in mathematics. However, in general, mathematics is one of the gate-keeping subjects for success in all fields of life. Mathematics is widely regarded as the mother of all subjects and a foundation for growth. To a considerable measure, a country's capacity to compete successfully in the global economy today is determined by its residents' mathematical literacy. According to Anamuah-Mensah (2007), the utilization of science, mathematics, and technology has been interlinked with improving productivity and wealth creation. This explains why it is crucial to have skilled human resources in science, mathematics, and technology as a nation. Therefore, the key to the economic development of Ghana depends on the development of a strong science, mathematics, and technology base.

Udousoro (2011) opines a negative relationship between the perceived and actual learning difficulties and that teacher should put effort into learning how pupils view geometry, as this knowledge can help improve student learning.

For this reason, what the critical area educational experts should target is the difficulties perceived by students concerning geometry in general. Thus the difficulty level of geometry programs should be seriously addressed. With this, every student has a level of developmental ability that must be first enhanced at the elementary level. Due to the importance of geometry in mathematics, most teachers, without a glance at shapes and solid forms, teach the subject to the best of their knowledge but do not provide the underlying concepts of geometry to the student's level of understanding. This sometimes creates the perceived difficulty of geometry for students.

The study of geometry is so important because it is associated with more academic and career opportunities and, at the same time, acts as one of the critical filters for entry into higher education programs and even in the world of work (Anamuah-Mensah, 2007). Thus, geometry spans the physics, engineering, and technology phase, and without sufficient knowledge in geometry, one may not climb the academic ladder. The mastery of geometry materials for the junior high school students that has remained relatively low might be caused by several factors, and these factors might come from the learning process, students' internal aspect, and teachers' internal aspect. According to Tambychik, Subahan, and Meerah (2010), most students have been weak in the following mathematical skills: visual-spatial, information, shape orientation, inter-problems relationship establishing, memorizing ability, and interrelated facts memorization. More specifi- 
cally, students have difficulties in learning geometry materials because of several matters. According to Kivkovich (2015), the difficulties that students experience in geometry are related to understanding mathematical language in geometry and associating it with prior knowledge. Other causes of students' difficulties in learning geometry have also been provided by Gloria (2015). According to her study, these causes have been the weak concept mastery, the weak understanding of mathematical skills, and the lack of students' enthusiasm toward the studied branch; altogether, these causes might trigger difficulties and negative responses toward the lesson.

\subsection{Statement of the Problem}

The importance of mathematics to an individual and society is acknowledged worldwide (Githua, 2013). Geometry is among the critical subjects in the curriculum of most countries. This is because the world and its structures are composed of geometrical codes that need to be decoded to solve problems. For instance, the use of geometry in modeling how airplanes should fly and land on the sea, the movement of the solar systems in space is very keys for astronomers, the movement of the compass that direct the ships on the sea have some basis of geometry in their dealings.

In Ghana, core mathematics has been one of the criteria one must cross to enter a higher institution to pursue the program of his or her choice. Reports from the West African Examination Council (WAEC) indicate most students fear mathematics due to geometry, and as a result, this fear leads to most of them failing. Before this study, the researcher went through the terminal reports of the students in the selected school (Konongo Odumasi Municipal area), and it was realized that most of the students performed poorly in mathematics. Upon further interview with some contacted students, they shared their views that geometry was their blockade to performing better in mathematics.

Geometry runs through the mathematics syllabus from form one to form three. Some believed that the teachers do not teach the subject well, and others believed that the fear of mathematics alone prevents them from understanding geometry. Others shared their view that pressure from home disables them to learn more about geometry. This raised suspicions about the teaching and learning of geometry in mathematics class which calls for attention.

In order to solve the above issues, many schools of thought, scholars, and pieces of literature have been investigated and given thoughts of this problem (perceived difficulty of geometry). These scholars have presented ways and means by which most students perceived geometry difficulty in their educational endeavor. However, there seems that the problem remains a constant thing. With a particular reference to Senior High school students in the Asante Akim Central Municipal, their performance in Mathematics is a pain in the necks of their respective school authorities every year due to the perceived difficulty in geometry. This still makes the subject matter under investigation. Therefore, there is the need to shift attention from looking at the relationship between the perceived and actual 
difficulty of geometry and concentrate on the factors influencing the perceived difficulty of geometry in mathematics.

\subsection{Purpose of the Study}

The study investigates the factors influencing the perceived difficulties of studying geometry in Konongo Odumasi Municipal areain the Asante Akim Central Municipal.

\subsection{Research Objectives}

The specific objectives are:

1) To determine the significant factors that influence students' perceived difficulties in geometry.

2) To determine the difference in perceived difficulty of geometry between male and female students of Konongo Odumasi Municipal area.

3) To determine if there is an association between gender and significant factors influencing perceived difficulty in geometry.

\subsection{Research Questions}

1) What are the factors that influence students' perceived difficulty in geometry?

2) What is the difference in the perceived difficulty of geometry between male and female students of Konongo Odumasi Municipal area?

3) What is the association between gender and significant factors influencing perceived difficulty in geometry?

\subsection{Significance of the Study}

This study is relevant as it adds value to the mathematics literature as there are only a few studies in Ghana examining the perceived difficulties in the study of Mathematics. By addressing students' difficulties in geometry, this study fills a gap in prior literature that has been restricted to addressing students' difficulties towards Mathematics education. The suggestion from the research questions will provide the foundations for any Mathematics education for future studies.

Again, the responses from the respondents will help standard setters to strengthen policies regarding the study of geometry in mathematics. This study also helps students in high schools to adopt strategies that will help them improve the level of geometry education rendered to the students, which helps prepare the students better for employment and the pressures that come with it.

\subsection{Limitation of the Study}

This study was restricted to the objectives and variables of the research and data from the students in the Konongo Odumasi Municipal areain the Asante Akim Central Municipality within the Ashanti Region of Ghana. Some constraints characterize the research work. Some of these setbacks include the time and wil- 
lingness of the students to respond to the questionnaires.

\section{Research Design and Methodology}

The research design refers to the method and processes that are adopted in collecting and analyzing data. The study adopted the descriptive survey design to investigate the factors that influence the perceived difficulties in geometry. The descriptive research design allows for much flexibility and allows the researcher to examine the phenomenon's boundaries (Neuman, 2014). The descriptive design reveals the connection between the factors influencing the perceived difficulty in geometry and the perceived difficulty of geometry. Similarly, a descriptive research design is used in this study because it enabled the researcher to collect data from a sample of informants that will be used to investigate the factors influencing the perceived difficulties in geometry. This design was used in this study because it enabled the researcher to collect information from a sample of students using questionnaires, interview guides, and observation schedules.

\subsection{Population}

Best and Kahn (1999) and Orodho (2012) contend that the target population is any group of individuals who have one or more characteristics in common that interest the researcher. Senior high school students in the Konongo Odumasi Municipal area were of interest to the researcher due to its proximity. Therefore, the target population consists of all senior high school students in the Konongo Odumasi Municipal area.

\subsection{Sample and Sampling Procedures}

A sample represents the target population and is an essential feature of any empirical study in which the goal is to make inferences about a population. A sampling technique is needed to achieve a population subgroup that is representative enough of the population, and then a calculated sample is required. Also, Slavin (1984) observes that due to time, funds, and energy limitations, a study can be carried out from a carefully selected sample to represent the entire population. The sampling technique appropriate for the study was the stratified sampling technique. The appropriateness of this technique is that the population is heterogonous (male and female students), and the objectives require that differences in gender concerning the perceived difficulty of geometry must be determined.

In all 150 students were used for the studies, these included Eighty-three (83) males, and sixty-seven (67) females.

\subsection{Data Collection Instrument}

The researcher used questionnaires to collect data from the students on factors influencing the perceived difficulties in geometry in Konongo Odumasi Municipal area. Best and Kahn (1999) and Orodho (2012) contend that questionnaires 
enable the person administering them to explain the purpose of the study and the meaning of the items that may not be clear. The study used questionnaires to ensure anonymity, permit standardized questions, have uniform procedures, provide time for subjects to think about responses, and easily score. The questionnaire consisted of three (3) sections captioned as Section A, Section B, and Section $\mathrm{C}$. The first section focused on the students' background information; the second section concentrated on the factors affecting the perceived difficulties in Geometry, and the third section focused on the questions concerning the perceived difficulty in Geometry.

\subsection{Data Collection Procedures}

As mentioned earlier, the researcher used questionnaires to collect data from the sample of the population. Questionnaires were administered to the selected students. A good rapport was established with the students to ensure that no one was under duress to answer the questions. The researcher assured them that information provided on the questionnaires was used for academic purpose only.

The data was collected at a time when students were less busy. The questionnaires were given to students while on a short break from a long hour of teaching.

When they were about twenty minutes to end the lessons, some of the instruments were given to the teachers to distribute to their students. This process continued for a week until all the questionnaires were answered.

\subsection{Ethical Consideration}

This study considered ethical values to ensure that the processes involved in this study are excellent and acceptable. The people to be investigated were assured of confidentiality issues concerning the data that they gave. Permission to conduct the study was also sought from the Municipal authorities and all participants of this study.

\section{Results and Discussions}

The research gathered data from the field using questionnaires. Using SPSS, the data were edited and coded into the software (SPSS). The results presented are analyzed using regression, correlation, and independent $\mathrm{t}$-test by the objectives. The minimum required sample size was 150, but the researcher distributed 160 questionnaires online, but 155 were returned. Out of the returned cases, the researcher used the minimum required sample size for the data analysis. The results are therefore presented below.

\subsection{Background Information of Respondents}

The respondents were asked to answer questions on their gender, level of study, the program of study, and level of parents' education. The results are presented in Table 1 below. 
Table 1. Background information of respondents.

\begin{tabular}{|c|c|c|c|c|}
\hline Variable & Frequency & Percentage & Mean & Std. \\
\hline \multicolumn{5}{|l|}{ Gender } \\
\hline Male & 83 & 55.3 & - & - \\
\hline Female & 67 & 44.7 & - & - \\
\hline \multicolumn{5}{|l|}{ Level of Respondent } \\
\hline Form 1 & 29 & 19.3 & - & - \\
\hline Form 2 & 34 & 22.7 & - & - \\
\hline Form 3 & 87 & 58 & - & - \\
\hline \multicolumn{5}{|l|}{ Program of Study } \\
\hline Business & 48 & 32.0 & - & - \\
\hline General arts & 53 & 35.3 & - & - \\
\hline Home economics & 14 & 9.3 & - & - \\
\hline Visual arts & 2 & 1.3 & - & - \\
\hline General science & 33 & 22.0 & - & - \\
\hline \multicolumn{5}{|c|}{ Level of Parents education } \\
\hline Junior high & 36 & 24.0 & - & - \\
\hline Secondary & 42 & 28.0 & - & - \\
\hline Tertiary & 58 & 38.7 & - & - \\
\hline Others & 14 & 9.3 & - & - \\
\hline Size of family & 150 & 100 & 6.33 & 2.188 \\
\hline Total & 150 & 100 & & \\
\hline
\end{tabular}

Source: Field Survey (2021).

The students ask these background questions identified in Table 1 above. These were asked to aid in understanding the objectives in detail. From Table 1, it can be observed that the majority of the students were males.

Thus, the males dominated the research sample by $55.3 \%$, whiles the females formed $44.7 \%$ of the sample used. Also, it was realized that the majority of the respondents form 3 students with 58\% proportionality, followed by form 2 students who formed $22.7 \%$ of the sample and form 1 being the least.

The students were asked to identify their program of study, and it turned out that the majority (35.3\%) of the students were reading General Arts. The second dominated program of study was Business (which formed 32\% proportions), followed by general science (which formed $22 \%$ proportions). The least program read was Visual Arts. The majority of the respondents answered that the level of education of parents was tertiary. The next dominant level of parents' education was secondary and junior high with $28 \%$ and $24 \%$ proportions. These respondents' background information indicates that at least each respondent had an idea of geometry and associated perceived difficulties, and hence deviation from objectives is minimized totally. Again, the average family size was 6.33 , approx- 
imately 6 , with a standard deviation of 2.188 .

\subsubsection{Research Question One}

\section{"What are the factors that influence students' perceived difficulty in geome-} try?"

The first question of this study was to determine the factors that influence students' perceived difficulties in geometry. Regression analysis was run to obtain the factors and the significant factors that influence students' perceived difficulties in geometry, but before the regression, correlation analysis was done to establish a linear relationship. The results are presented in the following table.

From Table 2, it was realized that there is a strong correlation $(\mathrm{R}=0.57)$ between the dependent variable (perceived difficulty) and the independent variables (math anxiety, self-confidence, family structure, parents' education level, professional teacher training, and environmental factors).

Hence there is a linear relationship between the dependent variable and independent variables. To determine the significant factors, the sig. value ( $p$-value) in the table above was used. The values were compared with 0.05 significant level, and conclusions were made based on that. From Table 2, the model is significant $(p$-value $=0.000<0.05)$ at 0.05 significant level.

This shows that all the independent variables jointly influence the dependent variable. Moreover, the adjusted $\mathrm{R}^{2}$ indicates that the independent variables account for $28.9 \%$ of variations in the dependent variable.

From Table 2, the significant variables influencing the dependent variables are parents' educational level and environmental factors. These variables are significant at 0.05 because their $p$-value $=0.018$ and 0.000 , respectively, are less than 0.05 .

Therefore, at a $95 \%$ confidence level, the factors that influence perceived difficulties in geometry are parents' educational level and environmental factors.

Perceived difficulties can therefore be modelled as $=1.08+0.17+0.27$,

Table 2. Regression analysis.

\begin{tabular}{|c|c|c|c|c|c|c|c|}
\hline Model & & Std. error & & Sig & & & - \\
\hline Regression & - & - & - & 0.000 & 10.8 & 0.57 & 0.289 \\
\hline (Constant) & 1.08 & 0.283 & 3.832 & 0.000 & & & \\
\hline Math anxiety & 0.13 & 0.06 & 1.95 & 0.053 & & & \\
\hline Self-confidence & -0.092 & 0.08 & -1.21 & 0.227 & & & \\
\hline Family structure & 0.07 & 0.05 & 1.36 & 0.175 & & & \\
\hline Parents' educational level & 0.17 & 0.07 & 2.39 & 0.018 & & & \\
\hline Teacher professional & 0.02 & 0.09 & 0.27 & 0.786 & & & \\
\hline \multicolumn{8}{|l|}{ Training } \\
\hline Environmental factors & 0.27 & 0.07 & 4.03 & 0.000 & & & \\
\hline
\end{tabular}

Source: Field Survey (2021). Dependent Variable: Perceived Difficulties of Geometry Significant level at 0.05 . 
where $P D$ - perceived difficulties,

$P E L$ - parents' educational level,

EF-environmental factors.

\subsubsection{Research Question Two}

"What is the difference in the perceived difficulty of geometry between male and female students of Konongo Odumasi Municipal area?"

The two-sample $\mathrm{t}$-test was used to determine the difference in perceived difficulties between male and female students.

From Table 3, it can be seen that the mean perceived difficulty between male and female students are not the same. This shows that differences exist in perceived difficulties of Geometry in groups (male and female students).

To conclude the differences in perceived difficulty of geometry between male and female students for the pre-intervention phase, there is the need to conclude the variations in the two groups (males and females). Levene's test of variance is used in the test. The hypothesis of Levene's test is stated below.

Ho: Equal variance assumed,

H1: Equal variance not assumed,

Decision rule: reject $\mathrm{HO}$ if $p$-value $<0.05$.

From Table 4, with $=1.741$ and since the $p$-value $=0.189>0.05$, we fail to reject the null hypothesis (H0) and conclude that equal variances are assumed. Hence, the difference in variations among the groups is insignificant.

Therefore, we state the hypothesis for differences in perceived difficulty below and conclude using the result of Levene's test and the $t$-test.

Ho. There is no difference in perceived difficulty between male and female students at Konongo Odumasi Municipal area,

H1: There is a difference in perceived difficulty between male and female students at Konongo Odumasi Municipal area,

With equal variance assumed and $(=-2.822, d f=148)$, since the $p$-value $=0.005$.

Table 3. Group statistics.

\begin{tabular}{ccccc}
\hline & Gender & Mean & Std. deviation & Std. error mean \\
\hline Perceived & Male & 2.2700 & 0.60800 & 0.06700 \\
Difficulty & Female & 2.5600 & 0.64700 & 0.07900 \\
\hline
\end{tabular}

Source: Field Survey (2021).

Table 4. Test of differences in perceived difficulty between male and female students.

\begin{tabular}{|c|c|c|c|c|c|c|}
\hline & & \multicolumn{2}{|c|}{$\begin{array}{c}\text { Levene's test } \\
\text { of variance }\end{array}$} & \multicolumn{3}{|c|}{$t$-test for equality of means } \\
\hline & & & Sig. & & $\mathrm{df}$ & Sig. \\
\hline Perceived & Equal variance assumed & 1.741 & 0.189 & -2.802 & 148 & 0.006 \\
\hline Difficulties & Equal variance not assumed & & & -2.784 & 137.43 & 0.006 \\
\hline
\end{tabular}

Source: Field survey (2021). ${ }^{\star}$ Significant level at 0.05 . 
0.05 we reject the null hypothesis $\mathrm{HO}$ and conclude that there is a difference in perceived difficulty of geometry between male and female students of Konongo Odumasi Munipal area.

\subsubsection{Research Question Three}

"What is the association between gender and the significant factors influencing perceived difficulty in geometry?"

The final objective of the study was to determine if there is an association between gender and the factors influencing perceived difficulty in geometry. This was to look at the association between gender and the significant factors determined in the second objective above. The Spearman's rank correlation was used to determine the association due to the categorical nature of the dependent variable (gender). The results are presented in Table 5 below.

From Table 5, it was realized that there is a weak positive linear association between gender parent's educational level and this association is significant because the $p$-value $=0.015<0.05$. Also, there is a weak positive linear association between gender and environmental factors and this association is not significant at 0.05 level because the $p$-value $=0.738>0.05$. Hence, it is found that there is no association between gender and environmental factors, but there is an association between gender and parent's level of education.

Thus, among the significant factors that influence perceived difficulty in geometry, parent's level of education matters for one's gender. Also, there were differences in perceived difficulty of geometry between male and female students, and there was an association between gender and parent's educational level.

\subsection{Discussion}

It was found that the majority of the respondents were males and the predominant programs of study at Konongo Odumasi Municipal area were General Arts followed by Business and also, most of the students were in their final year (form three). The demographic background of the respondents indicates that the research was male-dominated. This may be that subjects such as geometry in mathematics get more challenging for female students than male students, and as

Table 5. Association between gender the factors influencing perceived difficulty of geometry.

\begin{tabular}{cccc}
\hline & Parents' educational level & Environmental factors & Gender \\
\hline Parents' & 1 & & \\
educational level & & & \\
Environmental & 0.035 & 1 & \\
Factors & ${ }^{\star} 0.675$ & & 1 \\
Gender & 0.198 & 0.029 & \\
& ${ }^{\star} 0.015$ & ${ }^{*} 0.738$ & \\
\hline
\end{tabular}

Source: Field Survey (2021). * significant at 0.05 level. 
they progress to the next level, the female students either repeat or stop schooling due to failure in mathematics due to fear for geometry. This finding is with the findings of Karimi and Venkatesan (2017). They found out that geometry anxiety has a negative correlation with gender performance in mathematics. Especially, they argued that most females dislike geometry and have low performance in mathematics, of which they cannot progress.

Also, according to Hyde and Mertz (2016), more significant male variability concerning geometric mathematics is not ubiquitous. Instead, its presence correlates with several measures of gender inequality. Thus, it is largely an artifact of changeable sociocultural factors, not immutable, innate biological differences between the sexes.

However, the study found out that parents' educational level and environmental factors are the significant factors that influence perceived difficulty in geometry. In literature, Coleman et al. (1966) demonstrated that student achievement was correlated highly with family background factors such as income, parents' educational attainment, and family structure. These findings are in line with the finding of the study. Moreover, the study's finding reflects the background information on parents' level of education, of which the majority was tertiary level.

This supports the assertion of Campbell et al. (2000) in the literature reviewed that students who reported higher parental education levels tend to have average scores in geometry. Also, Schwartz (1999) argues that parents or guardians may be illiterate or have very little education and, therefore, not see the importance of doing well in geometry and furthering education. This may have been one of the factors influencing the perceived difficulty of geometry, but preceding literature proves otherwise. As argued by Hill and Craft (2013), parents with a higher level of education may have one way or the other faced challenges in geometry before and may discourage them from helping their wards with geometry assignments. This contributes to the perceived difficulty in geometry.

Again, Awanta (2000) posited that many students conform to peer group norms, contradicting those educators and teachers hold. Thus, most students see their peers as an inspiration for continuous study of a particular subject.

If peers perceive that geometry is complex, the probability of being influenced to have the same perception is high. This is concerning the finding of the study that environmental factors of the classroom influence the perceived difficulty of geometry. Furthermore, the argument of Awanta (2000) that "behavior in the classroom is bi-directional, that is, the participants' behavior is influenced not only by what the teacher does, but also what students do" supports the study's finding.

The study found a difference in perceived difficulty of geometry between male and female students of Konongo Odumasi Municipal area. This evidence suggests that students in this school have gender differences in terms of the perceived difficulty in geometry.

This indicates that the way female students of the school perceive geometry to be difficult is different from the way male students of the school perceive geo- 
metry difficulty. So perceived difficulty of geometry is dependent on the gender of the individual student.

Devine, Fawcett, Szücs, and Dowker (2012) found no gender differences in mathematics performance, but mathematics anxiety and test anxiety levels were higher for girls than boys. The finding of this research, therefore, adds to the literature on the perceived difficulty in geometry. Also, based on Devine et al. (2012) findings, the study can conclude that females perceive geometry more complex than males, creating gender differences in perceived difficulty geometry. Meanwhile, Hill and Craft (2013) revealed mounting evidence that both the magnitude of mean geometry gender differences and the frequency of identification of gifted and profoundly gifted females significantly correlate with sociocultural factors, including measures of gender equality across schools.

The study found out that there was a positive linear association between gender and parents' educational level.

This finding suggests that the gender of a student in the school moves in the same direction as parents' educational level in determining the perceived difficulty of geometry.

Thus, irrespective of the gender, as a parent or guardian's level of education increases, perceived difficulty of geometry between gender also increase. This phenomenon is described by Dryler (1998) same-sector effect.

Thus, it appeared to be somewhat stronger for fathers or parents and sons, while no same-sex effect is confirmed for girls. He added that parents educated within a specific field increase the probability of a child making a similar choice of subject difficulty at upper secondary school.

In the same line of the study findings, highly educated parents expected to be the most gender-egalitarian in attitudes and behaviors towards geometry positively associated with children's gender-atypical choice of geometry education in the class.

\section{Summary of Findings, Conclusions, and Recommendations}

\subsection{Summary}

The study conducted investigated factors influencing the perceived difficulties of geometry at Konongo Odumasi Municipal area. The objectives were to determine the factors that influence perceived difficulties of geometry, determine the difference in perceived difficulties of geometry between male and female students in the municipal, and finally determine the association between gender and the significant factors influencing perceived difficulties in geometry. The summary of the findings is itemized below;

1) The factors identified from the literature were mathematics anxiety, selfconfidence, family structure, parent educational level, professional teacher training, and environmental factors around the classroom. It turned out that the regression analysis identified parents' educational level and environmental factors 
as the significant factors influencing perceived difficulties in geometry at the secondary school. These factors had a positive influence on perceived difficulties in geometry. Thus, a unit change in each of these factors will lead to an additional increase in perceived difficulties in geometry.

2) The study found a difference in perceived difficulties in geometry between male-female students of the school understudy. Thus, how difficult one perceives geometry to depend on the gender of that individual, and the demographic characteristic of the study indicates that the school is male-dominated.

3) There was also a linear association between gender and the significant factors identified in objective one. However, it was revealed that there was no association between gender and environmental factors around the classroom. Instead, parents' level of educational level is associated with gender in determining perceived difficulties of geometry.

\subsection{Conclusion}

This study has established that parents' educational level and environmental factors are good predictors of perceived difficulties in geometry, supporting previous studies. It also shows that gender is a good factor in predicting the level of perceived difficulties of geometry among students in the classroom and that the differences in perceived difficulties of geometry between male and female students call for future research in literature.

The study's finding revealing an association between gender and parents' educational level adds to literature because this knowledge is needed for governments and education activists in their strategic education planning, especially, construction of mathematics syllabus. Educational advocates and stakeholders of education can rely on the findings of this research to minimize the perceived difficulties of geometry at the basic and secondary by incorporating policies that enable teachers and parents to create a sound environment for geometry study. Moreover, researchers in this area can rely on the findings of mathematics anxiety and students' overall performance.

\subsection{Recommendations}

1) Teachers and education institutions should ensure a sound environment that promotes geometry with ease without any difficulty.

2) Parental guidance is encouraged to create an atmosphere where wards will not have to look down upon parental educational level and be discouraged from asking for help in geometry.

3) There should be gender balance in terms of admission of students to the school, and teachers at the school should organize quizzes that involve more geometry to ease the perceived difficulties in geometry since it can make students more conscious of the need for geometry.

4) Students should be encouraged by the teachers at the school to partake in group discussions or allow their colleagues to solve geometry examples on the 
board because, per the literature reviewed, students learn quickly from their colleagues more than teachers.

5) Finally, the study's findings suspect that gender has a moderate role in the effects of perceived difficulties of geometry on overall performance. Therefore, lesson notes prepared by teachers should entail simple methods of solving geometry that bring students' minds together on the same level in the classroom.

\subsection{Suggestion for Future Study}

Looking at the study's findings, the researcher will suggest that future studies look at the effect of gender equality, parental control, and teacher's intrinsic motivation on geometry anxiety. It should also look at whether socio-economic factors moderate or mediate the relationship between mathematics anxiety and students' overall performance in final exams.

\section{Conflicts of Interest}

The authors declare no conflicts of interest regarding the publication of this paper.

\section{References}

Anamuah-Mensah, J. (2007). The Educational Reform and Science and Mathematics Education. A Keynote Address at the Stakeholders of Nuffic Practical Project Meeting.

Awanta, E. (2000). Helping Students Overcome Mathematics Anxiety. Journal of the Mathematics Association of Ghana, 12, 58-63.

Best, K., \& Hahn, B. (1999). Ethnical Guidelines in Participating Humans and Treatment of Persons in Research.

Campbell, R., Hombo, C. M., \& Mazzeo, J. (2000). NAEP 1999 Trends in Academic Progress: Three Decades of Student Performance. U.S. Department of Education.

Coleman, J. S. et al. (1966). Equality of Education Opportunity. US Department of Health Education, and Welfare, Office of Education.

Devine, A., Fawcett, K., Szűcs, D., \& Dowker, A. (2012). Gender Differences in Mathematics Anxiety and the Relation to Mathematics Performance While Controlling for Test Anxiety. Behavioral and Brain Functions, 8, Article No. 33.

https://doi.org/10.1186/1744-9081-8-33

Dryler, H. (1998). Parental Role Models, Gender, and Educational Choice. British Journal of Sociology, 49, 375-398. Educational Management, 3, 67-86.

https://doi.org/10.2307/591389

Ganal, N. N., \& Guiab, M. R. (2014). Problems and Difficulties Encountered by Students towards Mastering Learning Competencies in Mathematics. Journal of Arts, Science \& Commerce, 5, 25-37.

Githua, B. N. (2013). Secondary School Students' Perceptions of Mathematics Formative Evaluation and the Perceptions' Relationship to Their Motivation to Learn the Subject by Gender in Nairobi and Rift Valley Provinces, Kenya. Asian Journal of Social Sciences \& Humanities, 2, 174-183.

Gloria, C. C. (2015). Mathematical Competence and Performance in the Geometry of High School Students' Mathematics Concepts in Geometry. International Journal of Science and Technology, 5, 53-69. 
Hill, N. E., \& Craft, S. A. (2013). Parent-School Involvement and School Performance: Mediated Pathways among Socioeconomically Comparable African American and EuroAmerican Families. Journal of Educational Psychology, 95, 74-83. https://doi.apa.org/doi/10.1037/0022-0663.95.1.74

Hyde, J. S., \& Mertz, J. E. (2016). Gender, Culture, and Mathematics Performance. Proceedings of the National Academy of Sciences, 106, 8801-8807.

Karimi, A., \& Venkatesan, S. (2017). Mathematics Anxiety, Mathematics Performance and Overall Academic Performance in High School Students. Management and Labour Studies, 34, 556-562. https://doi.org/10.1177\%2F0258042X0903400406

Kivkovich, N. (2015). A Tool for Solving Geometric Problems Using Mediated Mathematical Discourse (for Teachers and Pupils). Procedia-Social and Behavioral Science, 209, 519 525. https://doi.org/10.1016/j.sbspro.2015.11.282

Neuman, W. (2014). Social Research Methods: Qualitative and Quantitative Approaches (7th ed.). Pearson Education Limited.

Orodho, A. (2012). Elements of Educational and Social Science Research Methods (2nd ed.). Kenezja Publisher.

Satriawan, \& Wutsqa, D. U. (2013). The Effectiveness of the Instruction with ComputerBased Interactive Learning Resources in Terms of Motivation and Mathematic. PYTHAGORAS: Jurnal Pendidikan Matematika, 8, 193-203.

Schwartz, S. H. (1999). A Theory of Cultural Values and Some Implications for Work. Applied Psychology: An International Review, 48, 23-47. https://doi.org/10.1111/j.1464-0597.1999.tb00047.x

Slavin, R. E. (1984). Component Building: A Strategy for Research-Based Instructional Improvement. Elementary School Journal, 84, 255-269.

Tambychik, T., Subahan, T., \& Meerah, M. (2010). Students' Difficulties in Mathematics Problem-Solving: What Do They Say? Procedia Social and Behavioral Sciences, 8, 142 151. https://doi.org/10.1016/j.sbspro.2010.12.020

Udousoro, U. J. (2011). Perceived and Actual Learning Difficulties of Students in Secondary School Mathematics. African Research Review, 5, 357-366.

https://doi.org/10.4314/afrrev.v5i5.28 